\title{
Entanglement of Higher Education and Strength of Open and Distance Learning in Nepal
}

\author{
Jiwak Raj Bajracharya* \\ Educational technology, International Christian University, Tokyo, Japan \\ *Corresponding author: Jiwakps@gmail.com \\ Received November 04, 2014; Revised November 14, 2014; Accepted November 19, 2014
}

\begin{abstract}
The purpose of this paper was to investigate the major entanglement of Higher education in Nepal and to find out the strength of Open and distance learning in Nepalese context. This study was based on empirical literature review including previous research, national and international reports regarding higher education of Nepal, whichhad been studied to investigate the major hurdles and then, analyzed the strength of Open and distance learning to overcome those hurdles. This paper found six major hurdles as 1) Lack of enough educational institutions (universities and campuses) around the country, 2) Limited capacity of admissions at public institutions, 3) Geographical barrier, 4) Highly expensive fees at private institutions, 5) Lack of national educational budgets, and 6) Strikes. Based on the characteristic and application of Open and distance learning, this paper suggests that, those six hurdles could be removed with the appropriate application of ODL programs to increase the strength of higher education in Nepal.
\end{abstract}

Keywords: open and distance learning, higher education, strength, hurdle

Cite This Article: Jiwak Raj Bajracharya, "Entanglement of Higher Education and Strength of Open and Distance Learning in Nepal." American Journal of Educational Research, vol. 2, no. 11 (2014): 1091-1093. doi: 10.12691/education-2-11-14.

\section{Introduction}

\subsection{Nepal}

Nepal is a landlocked and mountainous country located between China and India. Nearly $75 \%$ of the land is covered with high mountains, mid hills and rugged hills as seen in Figure 1.

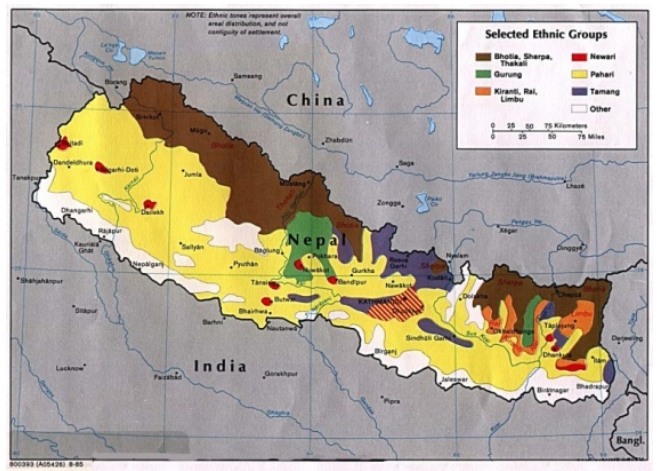

Figure 1. Physical map of Nepal

According to the [4] Central Bureau Statistics, Nepal was recorded to have a population of 26.49 million with $1.35 \%$ growth rate, among which $80 \%$ of the Nepalese people living in the rural areas [12]. Nepal is the country of multiple dimensions in terms of race/caste, ethnicity, language, religion, society and culture [15]. These diversities have helped Nepal to recognize distinctly a plural and as being a country with more than one hundred three distinct cultures, ethnic and caste groups. These caste and ethnic groups were also responsible for enrollment rate and drop out issues of certain group of peoples due to higher caste (also known as "the Brahmin") and lower caste (also known as "the Dalits [untouchables]") [5]. An educational report show that literacy rate of lower caste is 33.8\% whereas that of higher caste is $82 \%$ [3]. For this, many issues were responsible among which major one is; "discrimination between high caste and low caste within the educational institution" which results increasing number of drop out student from lowers caste [3].

\subsection{Higher Education}

Higher education is one of the most significant pillars of Global Competitiveness Index (GCI) to explain the country`s share of world markets and products. However, Nepal was ranked $10^{\text {th }}$ from the bottom (at 130 in the 139 country list) in the GCI 2011. One of the major contributing factors to poor GCI outcome was Nepal`s pitiful higher education.

The increased demand for higher education level in Nepal indicates the need for addressing the quality higher educational institutions [17]. Nepalese society is very much conscious about the quality of higher education. But, the insufficient education budgets from government and difficulties with geographical structure like high mountains are major problems [1]. That's why an alternative approach should be applied to enhance the higher education of Nepal. 
Nepal is one of the poorest and least developed countries in the world. With $30.8 \%$ of the population living below the poverty line [4]; it has a per capita income of 490 USD with annual growth rate $4.63 \%$. In 2013, Valente stated that Nepal`s political instability and political development have impeded the nation's economic development [19]. Asian Development Bank (ADB) stated that, Nepal's gross domestic product (GDP) grew by $3.6 \%$ in fiscal year 2013, slowing from $4.5 \%$ growth a year earlier [1]. Nepal is a country where the expenditure in higher education is lowest in the entire world. It accounts only $0.4 \%$ of GDP and only about $7 \%$ of public expenditure by government [17].

Although, Nepal has an increasing number of schools and colleges (mainly within urban areas), it is still suffering from a lack of physical schools and colleges in rural and mountainous regions. Three reasons can explain this situation: lack of governmental budget, unique landscape of the country, and low level of awareness of the value of education.

Another barrier is excessive summer rainfall, floods, landslides, strong winds as indicated by the United Nations Field Coordination Office (UNFCO) as the major issues that causes great problems for conducting physical schools and colleges in local areas.

Yet another important factor hindering the development of education is the high rate of conflict among political parties including strikes, involving students into those strikes and lack of general awareness toward education [2].

Although there is rapid growth in the number of available places in higher education, access is still very limited. According to the University Grant Commission (UGC) only about $13.1 \%$ of the population enter higher education in Nepal [18] which is behind its neighboring country India, which has Gross Enrollment rate (GER) of around 19\% [11]. The proportion of Nepalese entering higher education is also seriously below the world average (24\%) [11].

The 2011 annual report published by UGC mentioned that, the countries do have 410,000 students enrolled at various levels (certificates to doctoral degree) of study at all the universities and medical institutions at Nepal [18].

Ministry of Education (MOE) figures the pass rate of School Leaving Certificate (SLC) which is taken at end of grade 10 and Higher Secondary Education Board (HSEB) which is taken at grade 12 , show steadily increasing numbers of qualifying for higher studies at university level [10]. In 2013, MOE reported that; the total numbers of students at higher secondary levels (grade 9-12) are $1,265,563$ and the total numbers of schools (grade 9-12) are 34,782. MOE also reported the increasing pass percentage of higher secondary schools [10]. Hence, Nepal needs to have the significant number of higher educational institution in the future.

Due to its geographical structure, there are vast differences in the enrollment rate within different regions (Hills, Terai and Mountains) of Nepal. Hills and Terai regions have enrollment rate as $62.2 \%$ and $34.9 \%$ respectively, whereas mountainous regions have $2.9 \%$ [10].

\section{Open and Distance Learning}

Open and Distance Learning (ODL) is often defined as an alternative way of education for those who were physically and/or geographically unfit to have a conventional or face-to-face education. Generally, the use of printed materials and electronic media like: radio, computers, etc. enable students to pursue their education without attending any face-to-face class. In fact, there have been serious discussions about the establishment of the Open University of Nepal (OUN) to increase access to higher education opportunities in Nepal. OUN is proposed to provide an internationally accredited quality education and to fulfill the existing higher education gaps. OUN is a large-scaled joint collaborative project between international agencies, international universities and government of Nepal. Committee of OUN proposed the objectives of OUN closing the gap in higher education demand through ODL, providing tertiary education to remote and rural areas including marginalized peoples and women, providing higher education opportunities to fulltime employees who are not able to advance their higher education, providing a mechanism to continue higher education for the peoples of Nepal who were temporarily or permanently living abroad, advance computer based learning for socio-economic improvement [6].

Indeed, the quality of programs and degrees awarded by ODL institutions is indicated as one of the controversial issues. One example could be "Karnataka State open university" of India which admits that their technical and medical courses were illegal and decided to close those courses [13]. However, evidences show that these controversial issues can be reduced by providing and implanting the Quality Assurance (QA) framework including the set of QA standards for ODL through accredited QA agencies/professional ODL associations and establish an effective rules and regulation to implement those QA standards. One example can be found in the case of The Open University of UK (OUUK), one of the best known universities in UK for the quality of teaching. OUUK applies the asset of rigorous QA standards offered by "The UK Quality Code for Higher Education.”

Globally ODL is expanding continuously with the development of the Internet, increased information competencies, and reduced barriers to accessing and using the Internet [14]. This phenomenon can be slowly observed in Nepal.

ODL started in Nepal when The College of Education launched “The Radio Education Program" for teacher training in 1957, and promoted adult education through "Radio Nepal”, "FM radios" and “TV”. One more ODL program was launched in 1976 in the "Institute of Education" affiliated to TU, employing a radio broadcast approach and is used mainly to support teacher training activities [15]. This was discontinued in 1980 and replaced with the Radio Education Teacher Training (RETT) Project that offers a basic teacher training primary education certificate/diploma course in Nepali language. In 1998, there were 1,800 students enrolled in this course [15].

\section{Conclusion}

The Nepalese society is very much conscious about the quality of higher education. But, the insufficient education 
budgets from government and difficulties with geographical structure like high mountains are major problems to have a sufficient number of higher educational institutions with in all around the country. That's why an alternative approach should be applied to enhance the higher education of Nepal. Indeed, ODL could be an alternative approach.

Even though Nepal does have some ODL institutions, there is still a lack of trust in ODL in higher education community. In fact, these ODL institutions using their own QA framework to maintain the quality issues, which is proposed by their affiliated universities. Like ODL institutions like: International Center for Academics (ICA) follows a QA standard of IGNOU, India [7] whereas the Kathmandu University of School of Education Distance (KUSOED) follows QA standards of Kathmandu University (KU) [8]. Hence, the main problem is that all the standards which were excellent in a foreign country like India, might not be applicable in Nepal to some extent because of teaching material, code of ethics of professional bodies, difference in law [16]. Similarly, standards applicable for conventional educational system might not be appropriate for ODL because ODL is unique in character [9].

In most of the Asian countries, quality issues of ODL are managed by MOE/ higher education council or UGC by implementing Quality Assurance (QA) framework. Most of the countries in Asia does have QA framework for conventional educational system as well as for ODL [9]. But in Nepalese context, there are no authorized governmental or private agencies introducing QA framework for ODL for the implementation.

The increased demand for ODL services at higher education level in Nepal indicates the need for addressing the quality issue at the early stage of ODL development. Hence a formal QA policy framework including QA standards need to be studied and prepared before its wider implementation.

Countries like: Bangladesh, India and Pakistan have already established mega open universities and managed their ODL quality via publicly supported QA agencies [9]. However, Nepal has an ODL vision, ODL policies for schools and higher education, a plan to establish Open University, and few ODL institutions. But in these efforts, no QA framework considerations have been seriously discussed and no QA standards for ODL have been developed. Hence, a formal QA framework including appropriate QA standards need to be studied and prepared before its wider implementation to enhance the higher education in Nepal.

Unfortunately, the quality of ODL components in higher education in Nepal has not been assessed for public accountability and self-improvement.

This study suggests that QA framework and QA standards need to be developed considering Nepal's higher education system which would be helpful to remove the hurdles of higher education with the implementation of ODL.

\section{Acknowledgement}

First and foremost, I would like to dedicate this paper to my daughter Jinu Bajracharya whose smiling face always motivate me to work hard.

\section{References}

[1] ADB. (2013). Asian Development Outlook, 2013.

[2] Aryal, M. (2013, Jul 09). NEPAL: SCORING LOW ON QUALITY EDUCATION. Global Information Network. Retrieved from http://search.proquest.com/docview/1399169143?accountid=1010 5

[3] Bishwakarma, M,H.,(2011)Comparative Study of Dalit Education in Nepal. Retried from http://dx.doi.org/10.2139/ssrn.1822163

[4] CBS. (2012). National Population and Housing Census 2011. Retrieved from http://unstats.un.org/unsd/demographic/sources/census/2010_PHC /Nepal/Nepal-Census-2011-Vol1.pdf

[5] Dave. (2012). The decaying decadence of Nepal's caste system. Retrieved from http://www.thelongestwayhome.com/blog/nepal/nepalese-castesystem-culture-in-nepal-today/

[6] Dhakal, P., Adhikari, A., \& Rasali, D. (2010). A Proposal for an Open University of Nepal for Providing Higher Education to the Rural and Marginalized People. Himalayan Research Papers Archive. p. 3.

[7] ICA. (2013). Retrieved from http://www.ica.edu.np/

[8] KUSOED. (2011). Retrieved from http://distance.kusoed.edu.np/

[9] Latchem, C., \& Jung, I. (2009). Distance and blended learning in Asia. Routledge.

[10] MOE. (2013). Ministry of Education and Sports, Sano Thimi, Kathmandu, Nepal, Education In Nepal 2013.

[11] Mok, K. H., Yu, K. M., \& Wu, A. M. (2013). 8 The internationalization of higher education in Malaysia and South Korea. Internationalization of Higher Education in East Asia: Trends of Student Mobility and Impact on Education Governance, 138.

[12] Nepal Tourism Board. (2012). Mt. Everest \& More--: Pokhara. Nepal Tourism Board.

[13] Open University abolishes technical, paramedical courses. (2014, Aug 06). The New Indian Express Retrieved from http://search.proquest.com/docview/1551225352?accountid=1010 5

[14] Phipps, R., \& Merisotis, J. (2000). Quality on the line: Benchmarks for success in internet-based distance education. ().Institute for Higher Education Policy, Suite 400, 1320 19th St. NW, Washington, DC 20036; Retrieved from http://search.proquest.com/docview/62307731?accountid=10105

[15] Pradhan, L. (2012). Distance Education in Nepal. Journal of Educational and Social Research, 69.

[16] Sutton, L. M. (2012). Factors affecting quality discourse and knowledge construction in an online university course. (Order No. 3504887, North central University). ProQuest Dissertations and Theses, $162 . \quad$ Retrieved from http://search.proquest.com/docview/1013716602?accountid=1010 5. (1013716602).

[17] TU. (2013). TU Today Annual Publication. Kathmandu: The Author.

[18] UGC. (2012). Education Management Information System: Report on Higher Education 2010/2011. Sanothimi, Bhaktapur: The Author.

[19] Valente, C. (2013). Education and civil conflict in nepal The World Bank, Policy Research Working Paper Series: 6468. Retrieved from http://search.proquest.com/docview/1416035850?accountid=1010 5 